\title{
Immunoexpression of claudins 4 and 7 among invasive breast carcinoma subtypes: A large diagnostic study using tissue microarray
}

\author{
ANGELA FLÁVIA LOGULLO ${ }^{1}$, FATIMA SOLANGE PASINI ${ }^{2}$, SUELY NONOGAKI ${ }^{3}$, \\ RAFAEL MALAGOLI ROCHA ${ }^{4}$, FERNANDO AUGUSTO SOARES ${ }^{5}$ and MARIA MITZI BRENTANI ${ }^{6,7}$
}

${ }^{1}$ Pathology Department, Federal University of São Paulo (UNIFESP), São Paulo, SP 04023-062;

${ }^{2}$ Radiology and Oncology Department (LIM24), São Paulo University, School of Medicine (FMUSP), São Paulo, SP 01246-903; ${ }^{3}$ Department of Pathology, Adolfo Lutz Institute, São Paulo, SP 01246-000; ${ }^{4}$ Antonio Prudente Foundation, Hospital AC Camargo, São Paulo SP 01509-020; ${ }^{5}$ Discipline of Pathology, Odontology School, São Paulo University (FOUSP), São Paulo, SP 05508-000; ${ }^{6}$ Radiology and Oncology Department (LIM24), São Paulo University, School of Medicine (FMUSP), São Paulo, SP 01246-903; ${ }^{7}$ Pathology Department, A.C. Camargo Cancer Center, São Paulo, SP 01509-020, Brazil

Received January 19, 2018; Accepted July 24, 2018

DOI: $10.3892 / \mathrm{mco} .2018 .1685$

\begin{abstract}
Molecular phenotyping and tissue microarray (TMA) studies have identified distinct invasive breast carcinoma subtypes: Luminal A, luminal B, enriched with overexpressed human epidermal growth factor receptor 2 (HER-2) and triple-negative, i.e., negative for HER-2, as well as for estrogen and progesterone receptor (ER and PR, respectively) expression. These subtypes are useful in clinical management, since they bear distinct prognoses and predictive responses to targeted therapy. However, although molecular profiling provides important prognostic indicators, breast cancer risk stratification remains a challenge in triple-negative cases. What is referred to as claudin-low subtype was identified as a triple-negative subset that is associated with more aggressive tumor behavior and worse prognosis. However, the immunohistochemical expression of claudins has not yet been standardized. Our objective was to verify whether the immunoexpression of claudins 4 and 7 (the main claudins specifically expressed in human breast tissue) in TMA is associated with survival and prognosis in luminal A, HER-2 and triple-negative molecular subtypes. In this diagnostic study, we investigated ER/PR receptor status, HER-2, claudin 4 and 7 expression and stem cell CD44/24 profiles, and verified the association with prognosis and survival outcomes in 803 invasive breast carcinoma cases arranged in four TMAs. Among these, 503 $(62.6 \%)$ were positive for claudin 4 and 369 (46.0\%) for claudin
\end{abstract}

Correspondence to: Dr Angela Flávia Logullo, Pathology Department, Federal University of São Paulo (UNIFESP), Rua Botucatu, 740-CEP, São Paulo, SP 04023-062, Brazil

E-mail: waitzberg.angela@gmail.com

Key words: claudin 4, claudin 7, breast carcinoma, immunohistochemistry, tissue microarray analysis
7. Claudin 4 exhibited the lowest expression in luminal A and triple-negative subtypes, and the highest frequency of expression in HER-2-enriched subtypes, whereas claudin 7 staining was not associated with any subtype. The stem cell phenotype was not associated with subgroups or claudins 4 and 7. Claudin immunoexpression profile was not able to distinguish between patients with better or worse prognosis, and it was not correlated to triple-negative cases. Therefore, it may be concluded that the immunoexpression of claudins 4 and 7, individually or within the usual immunohistochemical context (ER, PR and HER-2), does not provide additional prognostic information on breast cancer subtypes.

\section{Introduction}

The possibility of applying targeted therapies in oncology introduced a new era of tailor-made treatments for breast cancer. The currently available therapies are indicated based on the morphological and genetic characteristics of the tumor $(1,2)$. Novel molecular techniques of gene expression profiling and microarray analysis enabled the identification of distinct invasive breast cancer (IBC) molecular subtypes, such as luminal A, luminal B, tumors enriched with human epidermal growth factor receptor 2 (HER-2) and triple-negative tumors. Luminal A is a subtype positive for estrogen and progesterone receptors (ER and PR, respectively) and HER-2-negative, with low levels of Ki-67 expression. Luminal B is also positive for ER and PR, but negative or positive for HER-2, and with high levels of Ki-67. Triple-negative (or basal-like) tumors are ER- and PR-negative, as well as HER-2 negative. Finally, HER-2-enriched tumors are ER- and PR-negative, but HER-2-positive. These subtypes are useful in clinical management, since they bear distinct prognoses and predictive responses to targeted therapy (3-7). ER-positive tumors are associated with a better prognosis and are prone to respond well to hormone therapy (3-5) in terms of disease-free and overall survival $(7,8)$, while patients with triple-negative tumors have a poor prognosis (6). 
In clinical practice, immunohistochemical profiling including three important breast cancer markers (ER, PR and HER-2 status) is used to determine breast cancer subtypes $(1,3-5,9)$, and this panel is currently considered the best choice for breast cancer predictive pathological evaluation (1). However, although molecular profiling provides important prognostic indicators, breast cancer risk stratification remains a challenge for certain subtypes, such as the triple-negative subtype, which is the most complex (3-6) and is usually associated with a more aggressive tumor behavior and worse prognosis (6).

Research efforts in molecular microarray sub-stratification identified new subcategories within triple-negative cancers $(6,10)$. Among those, the 'claudin-low' subcategory has emerged as one of the most aggressive breast cancer profiles (11-13), being correlated to an enriched stem-cell component phenotype $(11,12,14)$.

Claudins are cell adhesion molecules and components of the tight junction complex, which regulate permeability between cells and maintain cell-cell integrity $(15,16)$, and their role in carcinogenesis and progression to metastasis currently constitutes an active research focus (17). Claudins are known to act as barriers for the diffusion of solutes between epithelial cells, participating in the regulation of water transportation, ions and certain macromolecules. Therefore, it is a reasonable hypothesis that claudins are likely to be involved in carcinogenesis (18).

The absence or low expression of claudins is associated with cancer development and reduced survival, due to the disruption of these tight junctions $(19,20)$. The 'claudin-low' subtype of breast cancer is characterized by the reduced expression of claudin mRNAs, mainly claudins 3,4 and $7(11,12,14,20)$. Claudin expression deregulation has been previously implicated in cancer and is associated with metastasis and cancer progression $(15,17)$, and low expression of claudins has been correlated to worse prognosis in breast cancer when assessed by RNA-based tests $(14,17)$.

However, the claudin superfamily of integral membrane proteins is composed of numerous isotypes $(15,16,18)$, and there is some heterogeneity in study results when claudin subtypes are evaluated. Claudin 1 has been identified as a novel survival factor in basal-like breast cancers, as downregulation of claudin 1 was shown to induce cell death in breast cancer cell lines (17). High claudin 4 expression has been associated with worse breast cancer-specific, recurrence-free and overall survival, even in patients receiving adjuvant tamoxifen therapy (21). In triple-negative breast cancer cases, downregulation of claudin $7(13,22)$ or a combination of high expression of CLDN4 with low expression of CLDN7, were identified as predictive factors of worse prognosis (19).

In this context, the aim of the present study was to verify whether the addition of claudin immunoexpression evaluation to the immunohistochemical profile standard panel for patients with breast cancer would improve its prognostic assessment potential. Our objective, therefore, was to determine whether the expression of claudins 4 and 7 (the main claudins specifically expressed in human breast tissue) in tumor microarray (TMA) analysis would be associated with survival and prognostic outcomes in a large cohort of patients with breast tumors of different molecular subtypes (luminal A, HER-2 and triple-negative).

\section{Materials and methods}

Design, setting and ethics. This diagnostic study was conducted in a large referral center for cancer treatment in Brazil, a philanthropic hospital, following approval of the local Ethics Committee. The hospital obtained informed consent forms from all patients and controls for using archived tissues for research at any time. Patient anonymity was guaranteed.

Tumor samples and clinical data. The study used archived tumor samples from all consecutive female patients who were diagnosed with IBC of no specific type (not otherwise specified, NOS) between January 1980 and December 2001 in Hospital A.C. Camargo (São Paulo, SP, Brazil). Patient characteristics are presented in Table I. Among these tumor samples, formalin-fixed and paraffin-embedded samples with paraffin blocks suitable for immunohistochemistry analysis, with a registry of clinical data in the medical records and follow-up information, were selected.

From these cases, four TMA blocks were built for analysis, as described below. Two experienced pathologists (AFL and FAS) reviewed all cases to confirm the diagnosis, histological grade and the nuclear grade according to the criteria of the Nottingham system (23), and cases were individually discussed to reach consensus when necessary.

TMA construction. The construction of TMAs followed standard procedures, as previously described (24). Briefly, 1-mm diameter cylinders from selected tumor areas of the donor paraffin blocks were extracted and inserted in order into the receptor blocks (Beecher Instruments, Silver Spring, MD, USA). Each case was sampled twice and all cylinders were distributed in four new blocks and stored at $4^{\circ} \mathrm{C}$. Subsequently, 4- $\mu \mathrm{m}$ sections were prepared for each marker for immunohistochemistry analysis. Healthy breast tissues were also collected and confirmed as negative for breast cancer on microscopic analysis to be used as controls ( $\mathrm{n}=4$, aged $50-75$ years). These negative controls were selected among patients who had undergone plastic surgery for aesthetic purposes, and whose examination results excluded cancer.

Immunohistochemical staining. Each TMA slide was stained with the following antibodies: Anti-ER (clone SP1; rabbit monoclonal, monoclonal, anti-human estrogen receptor, clone SP1; cat. no. MA1-39540; 1:50; Thermo Fisher Scientific, Inc., Waltham, MA, USA), anti-PR (clone PgR636; monoclonal mouse anti-human progesterone receptor; Clone PgR 636; cat. no. M3569; 1:500; Dako Agilent Technologies, Inc., Santa Clara, CA, USA), anti-HER-2 (polyclonal rabbit anti-human; c-erbB-2 Oncoprotein; cat. no. A048529-2; 1:2,000; Dako; Agilent Technologies, Inc), claudin 7 (polyclonal rabbit anti human; cat. no. PA1-37474; 1:400), claudin 4 (claudin 4 monoclonal antibody anti human clone 3E2C1; cat. no. 32-9400; 1:200, and claudin 4 polyclonal antibody anti human clone ZMD.306; cat. no. 36-4800; 1:200) (all from Invitrogen; Thermo Fisher Scientific Inc.), CD44 (monoclonal antibody anti human clone DF1485, 1:100; cat. no.: MAB5315; 1:100; Abnova, Taipei, Taiwan) and CD24 (monoclonal antibody anti human clone C-20; 1:100; cat. no. SC7034 clone C-20; 1:100; Santa Cruz Biotechnology, Inc., Dallas, TX, USA). 
Table I. Clinical and pathological characteristics of 803 breast cancer patients.

\begin{tabular}{|c|c|}
\hline Characteristics & Patient no. (\%) \\
\hline Age, years [median (range)] & $54(24-96)$ \\
\hline \multicolumn{2}{|l|}{ Hormonal status } \\
\hline Postmenopausal & $317(39.5)$ \\
\hline Pathological staging & $486(60.5)$ \\
\hline II & $395(49.2)$ \\
\hline III & $350(43.2)$ \\
\hline IV & $58(7.2)$ \\
\hline \multicolumn{2}{|l|}{ Histological grade } \\
\hline I & $103(12.2)$ \\
\hline II & $480(59.8)$ \\
\hline III & $218(27.1)$ \\
\hline Missing data & $2(0.2)$ \\
\hline \multicolumn{2}{|l|}{ Nuclear grade } \\
\hline 1 & $6(0.7)$ \\
\hline 2 & $249(31.0)$ \\
\hline 3 & $546(68.0)$ \\
\hline \multicolumn{2}{|l|}{ Tumor size } \\
\hline $\mathrm{T} 1+\mathrm{T} 2$ & $394(49.1)$ \\
\hline $\mathrm{T} 3+\mathrm{T} 4$ & $409(50.9)$ \\
\hline \multicolumn{2}{|l|}{ Lymph node metastasis } \\
\hline $\mathrm{pNO}$ & $268(33.1)$ \\
\hline $\mathrm{pN}+$ & $524(65.3)$ \\
\hline Missing data & $12(1.1)$ \\
\hline \multicolumn{2}{|c|}{ Molecular subgroup of the primary tumor } \\
\hline Luminal A & $500(62.3)$ \\
\hline HER-2 & $114(14.2)$ \\
\hline Triple-negative & $179(22.3)$ \\
\hline Missing data & $10(1.2)$ \\
\hline
\end{tabular}

Luminal A, ER- and/or PR-positive, HER-2-negative; HER-2, HER-2 positive; triple-negative, ER-, PR- and HER2-negative; pNO, no regional lymph node metastasis identified histologically; $\mathrm{pN}+$, malignant cells in regional lymph nodes.

In order to standardize the immunohistochemical staining for the primary antibodies, the antigen retrieval method (equipment for humid heat, $\mathrm{pH}$ and type of buffer), the dilution of primary antibodies and the visualization system were optimized. Paraffin-embedded sections and breast tumor array sections were deparaffinized in xylene and rehydrated through graded ethanols.

For deparaffinization, the slides containing the histological sections were kept in the oven for $24 \mathrm{~h}$ at $60^{\circ} \mathrm{C}$ and then were immersed in xylene at $60^{\circ} \mathrm{C}$ for $20 \mathrm{~min}$. They were then immersed in xylol at room temperature for $20 \mathrm{~min}$ and then rehydrated in ethanol in decreasing concentrations: $100 \%$ for $30 \mathrm{sec}, 85 \%$ for $30 \mathrm{sec}$ and $70 \%$ for $30 \mathrm{sec}$.

Following deparaffinization and rehydration of the TMA sections, antigen retrieval was performed in a pressure cooker (until boiling, which occurs at $\sim 60^{\circ} \mathrm{C}$ in São Paulo) using sodium citrate buffer (pH6) as retrieval solution. Following primary antibody incubation (for $0 \mathrm{~min}$ at $25^{\circ} \mathrm{C}$ ) and a polymer-peroxidase (Leica Microsystem GmbH, Wetzlar, Germany) amplification step was performed. No secondary antibody was employed. Antigen detection was carried out in a solution containing 3,3'-diaminobenzidine (Sigma-Aldrich; Merck KGaA, Darmstadt, Germany) and $6 \% \mathrm{H}_{2} \mathrm{O}_{2}$.

Counterstaining with Harris hematoxylin was performed, at $25^{\circ} \mathrm{C}$ for $30 \mathrm{sec}$ including positive controls in each staining reaction. The positive controls consisted of normal breast and neoplastic tissue known to express each of the antigens of interest. The primary antibody was omitted as a negative control in the same sample. All slides were observed in a light microscope (DM300; Leica Microsystems GmbH).

Immunohistochemistry analysis. In order to classify the tumors into breast cancer subtypes, ER and PR were evaluated according to Allred scoring (25). Immunoreactivity $\leq 2$ (or $<1 \%$ of positive tumor cells) was considered as a negative result for ER and PR.

Luminal A was considered as ER- and PR-positive and HER-2-negative, with low levels of Ki-67 expression $(<14 \%)$; luminal $\mathrm{B}$ was considered as positive for ER and PR, positive for HER-2 (3+/3), with a Ki-67 index $>14 \%$; triple-negative (or basal-like) tumors were ER-, PR- and HER-2-negative.

For HER-2 samples, the presence of reactivity in $<10 \%$ of the tumor cells was scored as 0 , and cases in which there was barely perceptible focal membranous staining were scored as 1 ; weak to moderate staining observed in $>10 \%$ of the tumor cells was scored as 2 , and a strong complete membranous staining continuously in $>10 \%$ of the tumor cells was scored as 3 . We considered the result to be positive only if the score was 3, according to American Society of Clinical Oncology of American Pathologists recommendations update $(26,27)$.

In the CD24/44 evaluation, the specimens with $<10 \%$ of positive cells were considered as CD24/44-negative, and as positive when the membranes were stained in a distinct, thin pattern, limited to the membrane, without cytoplasmic or nuclear reactivity for CD44, CD24, claudins 4 and 7 . CD24 is mainly detected in the cytoplasm. A HercepTest model was used for reporting results, and the scoring was as follows: 0 , totally negative; $1+, 1-10 \%$ positive neoplastic cells; $2+$, moderate staining in $10-30 \%$ of neoplastic cells; and $3+,>30 \%$ of strongly reactive neoplastic cells. Normal breast tissue usually exhibits a $2+$ pattern of claudin 7 expression and $1+$ or 0 for CD24 and CD44. Therefore, $3+$ was considered as overexpression of these markers in the present study.

As regards the claudin expression detection and classification methods, our analysis was based on the Lanigan et al study (21), which reported a 0-3+ pattern of claudin expression, and also previous studies of our group (28), stating that ' $\mathrm{CD} 44$ and claudin-7 were considered positive when membranes were stained in a distinct and delicate pattern without reactive cytoplasm or nuclei. We used a HercepTest model for reporting results and the scoring was: 0 , totally negative; $1+, 1-10 \%$ positive neoplastic cells; $2+$, moderate staining in $10-30 \%$ of neoplastic cells; and $3+,>30 \%$ of strongly reactive neoplastic cells. CD24 was detected mainly in the cytoplasm and scoring was conducted as for CD44.' This assay was performed once per patient. 

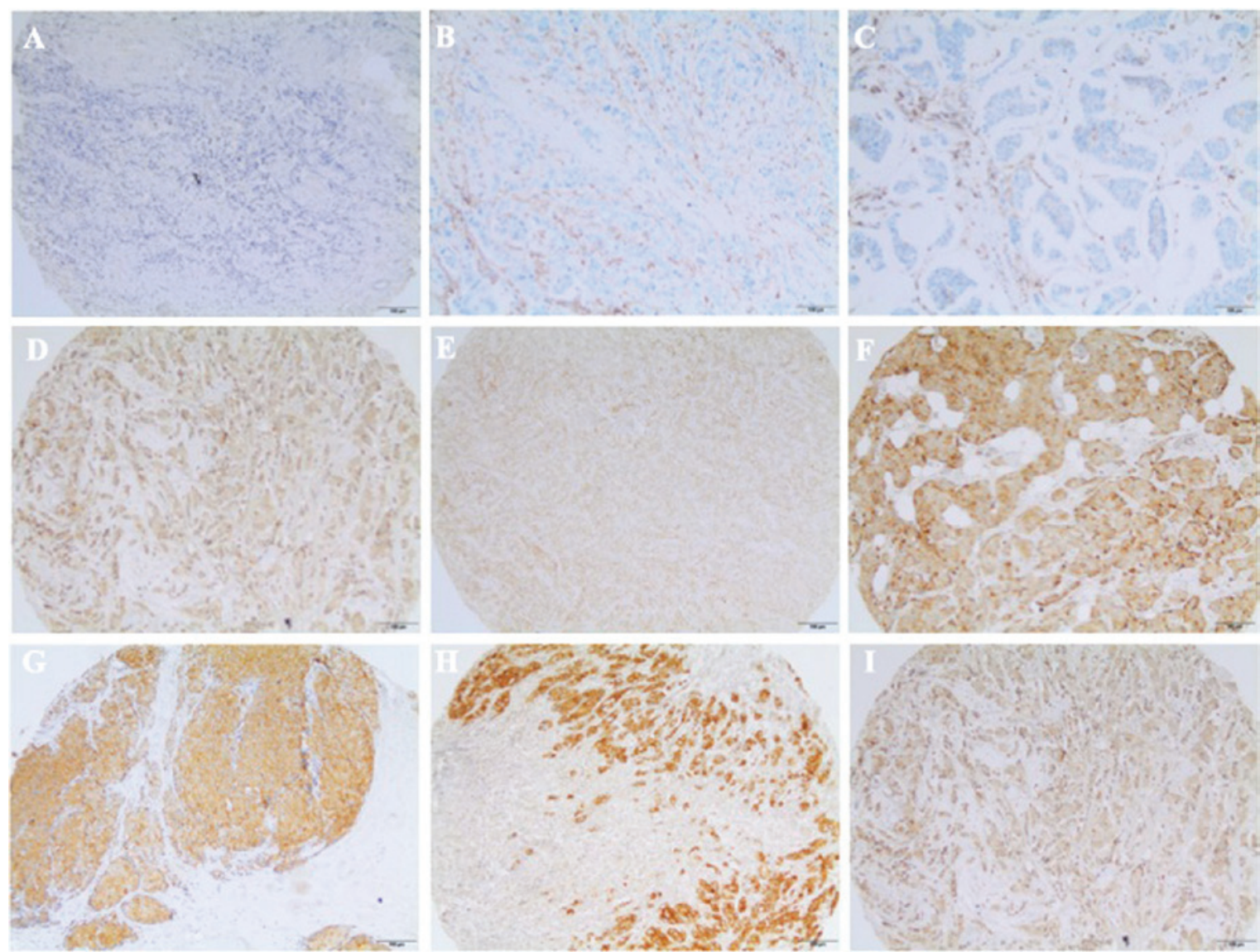

Figure 1. Examples of CD24, CD44 and claudin 4 and 7 immunostaining in mammary invasive carcinomas (scale bar, $100 \mu \mathrm{m}$ ). (A) Claudin-negative; (B) CD24-negative; (C) CD44-negative; (D) claudin 4 2+; (E) claudin 7 2+; (F) CD24-positive; (G) claudin 4 3+; (H) claudin 7 3+; (I) CD44-positive.

Statistical analysis. Data were presented as numbers (n) and percentage of cases. Associations between the immunohistochemical expressions and important clinicopathological variables were investigated using the Chi-squared test $\left(\chi^{2}\right)$. Survival probabilities were estimated by the univariate Kaplan-Meier method for univariate analysis and survival curves were compared using the log-rank test (Mantel-Haenszel method). SSPS version 10.0 for Windows (SPSS Inc., Chicago, IL, USA) was used for the analyses.

\section{Results}

Clinicopathological characteristics of the patients. During the study period, 880 patients with IBC were identified in our archives, and tissue samples and follow-up data were available for 803 of those patients. Further analysis of immunostained samples allowed for inclusion of 793 suitable cases in this study. The distribution of cases according to the clinical and pathological variables and ER, PR and HER-2 immunoexpression is shown in Table I. The present series included 500 cases with a luminal profile, 114 with HER-2 expression, and 179 triple-negative cases. In all these IBC cases, treatment involved mastectomy, radiotherapy and axillary lymph node dissection. ER-positive patients received hormone therapy, and the remaining were treated with chemotherapy. The median follow-up period was 70 months. At the final follow-up (July, 2007), 425 patients remained alive and 378 had succumbed to the disease.
Claudin expression in primary breast carcinomas. The claudin status according to immunohistochemistry expression is presented in Table II. The majority of cases (62.6\%) exhibited preserved claudin 4 or 7 expression and $46 \%$ were claudin 7-positive. Over $73 \%$ of the cases were positive for claudins 4 or 7 , and only $15.7 \%$ were negative for both claudins. Claudin 4 staining was restricted to epithelial cells and concentrated at the cell membrane, whereas claudin 7 exhibited a non-diffuse and punctate distribution. Examples of CD24, CD44 and claudin 4 and 7 immunostaining are shown in Fig. 1.

CD24/44 expression analysis revealed only $10.2 \%$ of cases with stem cell profile (CD44-positive/CD24-negative). The pattern of CD44 expression was mainly membranous, whereas CD24 was expressed predominantly in the cytoplasm.

No associations were observed between claudin 7 expression and the presence of ER/PR and HER-2. Claudin 7 expression was also not found to be associated with clinical or pathological variables, such as stage, tumor size or lymph node status in TMA analysis (Tables III and IV).

However, claudin 4 expression exhibited a direct association with histological and nuclear grade. The same progressive accumulation of claudin 4-positive cases was associated with lymph node status, meaning that, proportionally, more claudin 4-positive cases were concentrated at the positive lymph node category (Table III).

Among the ER-positive cases, which comprised the majority of the patients, $60.5 \%$ were claudin 4 -positive. 
However, almost $70 \%$ of the ER-negative cases were also associated with preserved claudin 4 expression $(\mathrm{P}=0.01)$. Similarly, although $53.7 \%$ of the PR-positive cases were claudin 4-positive, a high number of tumors $(67.1 \%)$ stained positive in the PR-negative samples $(\mathrm{P}=0.037)$. However, positive claudin 4 expression was more prevalent among HER-2 positive tumors $(\mathrm{P}<0.001)$ (Tables III and IV).

The frequency of claudin 4 and 7 expression in several combinations of CD44 and CD24 phenotypes was next analyzed. Claudin 4 expression exhibited no differences in frequency between possible combinations, while claudin 7 positivity was associated with the CD $44^{+} / \mathrm{CD} 24^{+}$and CD $44^{-} / \mathrm{CD} 24^{+}$ phenotypes in the sample $(\mathrm{P}=0.001)$ (Tables III and IV).

The expression of claudins 4 and 7 in breast carcinomas was examined according to previously defined subtypes of breast cancer patients. Claudin 4 was less expressed in the luminal A and triple-negative subtypes and exhibited the highest frequency of positive expression in HER-2-enriched tumors, whereas claudin 7 positivity was not associated with any of the breast cancer subtypes (Tables IV and V). When the presence of the $\mathrm{CD} 44^{+} / \mathrm{CD} 24^{-}$phenotype was investigated, we observed that the stem cell phenotype was not related to the defined subgroups.

We then investigated the possible prognostic value of claudin 4 and 7 expression. Considering all patients, claudin immunoexpression profile was not able to distinguish between patients with better or worse prognosis. As seen in Tables VI and VII, claudin 4 and 7 expression profiles were not associated with overall survival or disease-free interval. Among triple-negative cases (Table VIII) and luminal cases (Table IX), the immunoexpression of claudin 4 and 7 did not indicate clinical evolution; this was also true for the HER-2 subgroup (Table $\mathrm{X} ; \mathrm{P}=0.09$ ).

\section{Discussion}

In the present study, 803 IBCs were evaluated for claudin 4 and 7 immunohistochemical expression, in search for the possible role of these claudins as prognostic indicators, beyond breast cancer subtype profiling. The distribution of subtypes in our sample (62\% luminal, 14\% HER-2-positive and 22\% triple-negative) reflected the distribution in the literature $(4,29)$. However, in the present study, what is referred to as 'claudin-low' status (herein defined by the low expression of claudins 4 and 7) was not found to be associated with the triple-negative-like IBC subtype. We consider the status of any individual claudin to play a limited role in determining prognosis or providing predictive information in luminal A, HER-2 and triple-negative breast cancer subtypes, whereas it is of little value to the routine immunohistochemistry panel investigation for patients with breast cancer. Although suggested to act as a tumor supressor, high levels of claudin 1 have been observed in the aggressive triple-negative or basal-like cancer subtype $(30,31)$; in addition, the downregulation of claudin 1 has been found to be associated with ER positivity and poor prognosis $(31,32)$.

Indeed, the individual expression of claudins has been reported to be limited and controversial (33). Claudins 4 and 7 are the most commonly identified in breast tissue (33), and both have been reported as potential markers for clinical outcomes $(21,31,34-37)$. In the present study, although the
Table II. Frequency of claudin 4 and 7 and CD44/CD24 protein expression in primary breast carcinomas.

\begin{tabular}{lc} 
Biomarkers & Patient no. $(\%)$ \\
\hline Claudin 4 & \\
Negative & $288(35.9)$ \\
Positive & $503(62.6)$ \\
Missing data & $12(1.5)$ \\
Claudin 7 & \\
Negative & $355(44.2)$ \\
Positive & $369(46.0)$ \\
Missing data & $79(9.8)$ \\
CD44/CD24 & \\
-/- & $285(35.5)$ \\
+/+ & $126(15.7)$ \\
-/+ & $256(31.9)$ \\
+/- (stem cells $)$ & $82(10.2)$ \\
Missing data & $54(6.7)$ \\
\hline
\end{tabular}

majority of the evaluated IBC cases exhibited preserved claudin 4 and 7 expression, (62 and 46\%, respectively) the distribution of the claudin-low or negative cases did not correspond to the triple-negative molecular profile. Only $15.7 \%$ of the patients in this study were negative for both claudins, and this frequency is consistent with that reported in the literature $(11,14,38,39)$.

Claudin 4-negative cases (36\% of our total cases) were more common among the luminal profile cases $\left(\mathrm{ER}^{+}, \mathrm{PR}^{+}\right.$and HER-2), with a smaller amount in the triple-negative subtype, followed by the HER-2 expression enriched subgroup. The same pattern was verified on negative claudin 7 results, although without statistical significance. The most important finding in this study is the inverse association between claudin 4 and ER/PR expression, which indicates that he majority of claudin-negative cases $(71.3 \%)$ were actually clustered among the ER-positive cases, or luminal subtype. Szasz et al (40) also suggested that claudin 4 was less expressed in luminal cancers.

Myal et al (41) proposed a 'claudin-high' subtype, which comprises ER-negative tumors exhibiting high claudin 4 expression. Some studies $(21,30,36,39)$ reported that claudin 4 was associated with shorter disease-free survival in the luminal cancer group, an association not confirmed in our series. However, this feature must be further investigated in multivariate analyses in order to estimate the possible contribution of other prognostic variables in the association.

However, Lu et al (13) defined different criteria for considering cases as 'claudin-low': For these authors, five subtypes of claudins (1,3,4,7 and 8) should be altered for the status to be named 'claudin-low', and the authors reported that only $3 \%$ of claudin-low tumors belonged to the luminal phenotype. However, in the evaluation of other claudin-low characteristics in our study, such as the cancer stem cell-like phenotype in the negative cases, no association was found between the absence of claudin 4 and $\mathrm{CD}_{4} 4^{+} / \mathrm{CD} 24^{-}$and unfavorable prognostic parameters, including overall and disease-free survival.

Unexpectedly, previous results associating low claudin 4 expression with a better prognosis, particularly in 
Table III. Correlation between the expression of biomarkers in breast carcinoma and prognostic factors.

\begin{tabular}{|c|c|c|c|c|}
\hline \multirow[b]{3}{*}{ Clinicopathological data } & \multicolumn{4}{|c|}{ Markers } \\
\hline & \multicolumn{2}{|c|}{ Claudin 4} & \multicolumn{2}{|c|}{ Claudin 7} \\
\hline & Negative & Positive & Negative & Positive \\
\hline \multicolumn{5}{|l|}{ Histological grade, $\mathrm{n}(\%)$} \\
\hline I & $37(36.6)$ & $64(63.4)$ & $47(50.0)$ & $47(50.0)$ \\
\hline II & $197(41.6)$ & $197(58.4)$ & $214(49.9)$ & $215(50.1)$ \\
\hline \multirow[t]{2}{*}{ III } & $54(25.2)$ & $160(74.8)$ & $94(47.0)$ & $106(53.0)$ \\
\hline & \multicolumn{2}{|c|}{$P<0.001$} & \multicolumn{2}{|c|}{$\mathrm{P}=0.78$} \\
\hline \multicolumn{5}{|l|}{ Nuclear grade, n (\%) } \\
\hline 1 & $3(50.0)$ & $3(50.0)$ & $2(33.3)$ & $4(66.7)$ \\
\hline 2 & $112(45.7)$ & $133(54.3)$ & $118(51.8)$ & $110(48.2)$ \\
\hline \multirow[t]{2}{*}{3} & $173(32.2)$ & $365(67.8)$ & $235(48.0)$ & $255(52.0)$ \\
\hline & \multicolumn{2}{|c|}{$\mathrm{P}=0.001$} & \multicolumn{2}{|c|}{$\mathrm{P}=0.47$} \\
\hline \multicolumn{5}{|l|}{ Tumor stage, n (\%) } \\
\hline $\mathrm{T} 1+\mathrm{T} 2$ & $144(37.1)$ & $244(62.9)$ & $175(48.7)$ & $184(51.3)$ \\
\hline \multirow[t]{2}{*}{$\mathrm{T} 3+\mathrm{T} 4$} & $144(35.7)$ & $259(64.3)$ & $180(49.3)$ & $185(50.7)$ \\
\hline & \multicolumn{2}{|c|}{$\mathrm{P}=0.71$} & \multicolumn{2}{|c|}{$\mathrm{P}=0.88$} \\
\hline \multicolumn{5}{|l|}{ Lymph nodes, n (\%) } \\
\hline Negative & $110(41.7)$ & $154(58.3)$ & $118(49.4)$ & $121(50.6)$ \\
\hline \multirow[t]{2}{*}{ Positive } & $175(34.0)$ & $340(66.0)$ & $232(48.8)$ & $243(51.2)$ \\
\hline & \multicolumn{2}{|c|}{$P=0.04$} & \multicolumn{2}{|c|}{$\mathrm{P}=0.94$} \\
\hline \multicolumn{5}{|l|}{ Pathological stage, n (\%) } \\
\hline II & $147(38.0)$ & $240(62.0)$ & $179(49.7)$ & $181(50.3)$ \\
\hline III & $118(34.0)$ & $229(66.0)$ & $158(49.5)$ & $161(50.5)$ \\
\hline \multirow[t]{2}{*}{ IV } & $23(40.4)$ & $34(59.6)$ & $18(40.0)$ & $27(60.0)$ \\
\hline & \multicolumn{2}{|c|}{$\mathrm{P}=0.44$} & \multicolumn{2}{|c|}{$\mathrm{P}=0.46$} \\
\hline \multicolumn{5}{|l|}{ Estrogen receptor, n (\%) } \\
\hline Negative & $82(30.1)$ & $190(69.9)$ & $130(52.6)$ & $117(47.4)$ \\
\hline Positive & $204(39.5)$ & $313(60.5)$ & $224(44.2)$ & $251(52.8)$ \\
\hline & & & & \\
\hline Progesterone receptor, $\mathrm{n}$ & & & & \\
\hline Negative & $143(32.9)$ & $231(67.1)$ & 198 (49.6) & $201(50.4)$ \\
\hline Positive & $143(40.3)$ & $212(53.7)$ & $156(48.3)$ & $167(51.7)$ \\
\hline & & & & \\
\hline HER-2, n (\%) & & & & \\
\hline Negative & $262(37.9)$ & $429(62.1)$ & $301(48.9)$ & $314(51.1)$ \\
\hline Positive & $21(18.4)$ & $93(81.6)$ & $51(49.5)$ & $52(50.5)$ \\
\hline & & & & \\
\hline CD44/CD24, n (\%) & & & & \\
\hline$-/-$ & $111(39.4)$ & $171(60.6)$ & $168(64.4)$ & $171(60.6)$ \\
\hline$+/+$ & 47 (37.9) & $77(62.1)$ & $47(37.3)$ & $79(62.7)$ \\
\hline$-/+$ & $80(32.0)$ & $170(68.0)$ & $83(33.5)$ & $165(66.5)$ \\
\hline$+/-$ & $25(30.5)$ & 57 (69.5) & $52(65.8)$ & $27(34.2)$ \\
\hline & & & & \\
\hline
\end{tabular}

HER-2, human epidermal growth factor receptor 2; P-values were two-sided; bold print indicates statistical significance.

patients with luminal subtypes of breast cancer, have been reported (40). Paradoxically, claudin 4 positivity in our series was associated with poor prognostic factors, such as higher tumor grade, presence of positive lymph nodes and 
Table IV. Association between claudin 4 and claudin 7 expression, molecular subgroups and CD44/CD24 expression in invasive ductal breast carcinomas.

\begin{tabular}{|c|c|c|c|c|c|c|c|c|}
\hline \multirow[b]{2}{*}{ Variables } & \multicolumn{3}{|c|}{ Claudin 4-positive } & \multirow[b]{2}{*}{ P-value } & \multicolumn{3}{|c|}{ Claudin 7-positive } & \multirow[b]{2}{*}{ P-value } \\
\hline & $\mathrm{N}(\%)$ & OR & CI $(95 \%)$ & & $\mathrm{N}(\%)$ & OR & CI $(95 \%)$ & \\
\hline \multicolumn{9}{|c|}{ Molecular subgroup } \\
\hline Luminal A & $293(58.6)$ & - & - & & $239(65.3)$ & - & - & \\
\hline HER-2 & $93(18.6)$ & 3.0 & $1.8-4.99$ & $<0.001$ & $52(14.2)$ & 0.91 & $0.59-1.40$ & 0.68 \\
\hline Triple-negative & $114(22.8)$ & 1.22 & $0.86-1.76$ & 0.26 & $75(20.5)$ & 0.77 & $0.54-1.10$ & 0.16 \\
\hline \multicolumn{9}{|l|}{ CD44/CD24 } \\
\hline$-/-$ & $171(36.0)$ & - & - & - & $93(25.5)$ & - & - & \\
\hline$+/+$ & 77 (16.2) & 1.06 & $0.69-1.64$ & 0.78 & $79(21.7)$ & 3.04 & $1.95-4.72$ & $<0.001$ \\
\hline$-/+$ & $170(35.8)$ & 1.38 & $0.96-1.97$ & 0.08 & $165(45.3)$ & 3.59 & $2.49-5.17$ & $<0.001$ \\
\hline$+/-$ & $57(12.0)$ & 1.48 & $0.87-2.51$ & 0.15 & $27(7.4)$ & 0.94 & $0.55-1.59$ & 0.81 \\
\hline
\end{tabular}

OR, odds ratio; CI, confidence interval; luminal A, ER- and/or PR-positive, HER-2-negative; HER-2, HER-2-positive; triple-negative, ER-, PR- and HER-2-negative. P-values were two-sided; bold print indicates statistical significance.

Table V. Distribution of protein expression pattern according to molecular groups of locally advanced invasive ductal breast carcinomas.

\begin{tabular}{|c|c|c|c|c|}
\hline Variables & Luminal A & HER-2 & Triple-negative & P-value \\
\hline \multicolumn{5}{|c|}{ Claudin 4, n (\%) } \\
\hline Negative & 199 (70.3) & $21(7.4)$ & $63(22.3)$ & \multirow[t]{2}{*}{0.001} \\
\hline Positive & 293 (58.6) & 93 (18.6) & $114(22.8)$ & \\
\hline \multicolumn{5}{|c|}{ Claudin $7, \mathrm{n}(\%)$} \\
\hline Negative & $214(60.8)$ & $51(14.5)$ & 87 (24.7) & \multirow[t]{2}{*}{0.37} \\
\hline Positive & $239(65.3)$ & $52(14.2)$ & $75(20.5)$ & \\
\hline \multicolumn{5}{|c|}{ CD44, n (\%) } \\
\hline Negative & $338(61.3)$ & 75 (13.6) & $138(25.0)$ & \multirow[t]{2}{*}{0.02} \\
\hline Positive & $141(68.1)$ & $34(16.4)$ & $32(15.5)$ & \\
\hline \multicolumn{5}{|c|}{ CD24, n (\%) } \\
\hline Positive & $228(62.3)$ & $58(15.8)$ & $80(21.9)$ & \multirow[t]{2}{*}{0.62} \\
\hline Negative & $242(64.0)$ & $51(13.5)$ & $85(22.5)$ & \\
\hline \multicolumn{5}{|c|}{ CD44/CD24 } \\
\hline$+/+$ & $171(60.4)$ & 45 (15.9) & $67(23.7)$ & \multirow[t]{4}{*}{0.11} \\
\hline$+/-$ & $84(68.4)$ & $21(17.1)$ & $18(14.6)$ & \\
\hline$-/+$ & $157(61.8)$ & $30(11.8)$ & $67(26.4)$ & \\
\hline$-/-$ & $56(68.3)$ & $13(15.9)$ & $13(15.9)$ & \\
\hline
\end{tabular}

Luminal A, ER- and/or PR-positive, HER2 negative; HER-2, HER2-positive; triple-negative, ER-, PR- and HER-2-negative. P-values were two-sided; bold print indicates statistical significance.

ER/PR negativity, which is in agreement with previous reports $(13,21,31,40)$.

Some prior studies have demonstrated that immunohistochemical expression of claudin 4 was associated with the basal phenotype $(30,42)$ and triple-negative subtype (43). However, our results indicated that claudin 4 was mostly found among cases with the HER-2 subtype, and this finding is in agreement with others reports (22). These findings were substantiated by a logistic regression analysis, which found claudin 4 positivity to be significantly associated with HER-2 positivity. However, our findings were not indicative of a correlation between claudin expression and unfavorable prognosis.

There was no statistically significant association between the expression of claudin 7 and any of the clinicopathological parameters evaluated in our cases, contradicting previous studies reporting increased claudin 7 expression in ER-positive 
Table VI. Univariate analysis considering overall survival of breast cancer patients.

\begin{tabular}{|c|c|c|c|c|}
\hline Variables & Number of patients & Median survival (years) & $95 \%$ confidence interval & P-value \\
\hline \multicolumn{5}{|l|}{ Pathological stage } \\
\hline II & 395 & Not achieved & Not determined & \multirow[t]{3}{*}{$<0.001$} \\
\hline III & 350 & 6.0 & 4.9-7.1 & \\
\hline IV & 58 & 2.0 & $1.4-2.6$ & \\
\hline \multicolumn{5}{|l|}{ HER-2 } \\
\hline Negative & 679 & 12.0 & $9.8-14.2$ & \multirow[t]{2}{*}{0.008} \\
\hline Positive & 114 & 5.0 & $0.6-9.4$ & \\
\hline \multicolumn{5}{|l|}{ Estrogen receptor } \\
\hline Negative & 275 & 6.0 & $4.2-7.8$ & \multirow[t]{2}{*}{$<0.001$} \\
\hline Positive & 525 & 14.0 & $12.0-15.9$ & \\
\hline \multicolumn{5}{|c|}{ Progesterone receptor } \\
\hline Negative & 440 & 8.0 & $6.1-9.9$ & \multirow[t]{2}{*}{$<0.001$} \\
\hline Positive & 360 & 16.0 & $12.8-19.2$ & \\
\hline \multicolumn{5}{|c|}{ Molecular subgroups } \\
\hline Luminal A & 500 & 14.0 & $12.0-15.9$ & \multirow[t]{3}{*}{$<0.001$} \\
\hline HER-2 & 114 & 5.0 & $0.6-9.4$ & \\
\hline Triple-negative & 179 & 6.0 & $3.8-8.2$ & \\
\hline \multicolumn{5}{|l|}{ Claudin 4} \\
\hline Negative & 288 & 10.0 & $7.2-12.8$ & \multirow[t]{2}{*}{0.49} \\
\hline Positive & 503 & 12.0 & $9.7-14.3$ & \\
\hline \multicolumn{5}{|l|}{ Claudin 7} \\
\hline Negative & 355 & 11.0 & 8.6-13.4 & \multirow[t]{2}{*}{0.97} \\
\hline Positive & 369 & 12.0 & $9.3-14.7$ & \\
\hline \multicolumn{5}{|l|}{ CD44/CD24 } \\
\hline$-/-$ & 285 & 13.0 & $10.3-15.8$ & \multirow[t]{4}{*}{0.65} \\
\hline$-/+$ & 256 & 11.0 & 8.4-13.6 & \\
\hline$+/-$ & 82 & 9.0 & $5.4-12.6$ & \\
\hline$+/+$ & 126 & 12.0 & $9.5-14.5$ & \\
\hline
\end{tabular}

HER-2, human epidermal growth factor receptor 2; P-value was determined by the log-rank test; bold print indicates statistical significance.

and decreased expression in ER-negative breast tumors, or an association with high histological grade $(13,34,44,45)$. Preliminary results of our group were previously reported in a smaller number of cases, showing that claudin 7 was associated with shorter recurrence-free interval (28). However, in the present study, which included a larger number of cases, there was no observed association of claudin 7 with worse prognosis in the univariate analysis. Other authors demonstrated a distinct prognostic role for claudins 1,4 and 7 in other studies including a smaller number of patients $(13,21,37,40)$.

If the triple-negative subtype is prone to exhibit lack of adhesion molecules, particularly claudins, it may be hypothesized that epithelial-to-mesenchymal transition, frequently described in this context, may explain this phenomenon. The focus of this study has been on claudins 4 and 7, and it was concluded that the absence of these two distinct types of claudins did not confer a worse prognosis or lower survival rate in our series. It appears that cell adhesion abnormalities and aggressive behavior are not dependent on one single class of these proteins (46).
Triple-negative tumors are difficult to subclassify, as they are a very heterogeneous group. Since Hennessy et al (11) identified a potentially highly aggressive subtype of triple-negative breast cancers as 'claudin-low', efforts have been focused on differentiating those cases from the less severe triple-negative cancers. Recently, ER, PR and HER-2, the immunohistochemically detected tumor markers that are known to be of great value in the treatment of breast cancer, were incorporated into the AJCC Breast TNM Staging System (47) to refine prognosis. It would be very useful if claudin protein expression, based on reproducible immunohistochemical assays, could accurately identify the cases with worse prognosis among all triple-negative tumors. However, it appears that the protein expression in paraffin-embedded tissues does not reflect the claudin RNA level determined by microarray and, therefore, is not considered a safe evaluation for prognosis.

As the majority of data on claudin-low breast cancers were reported among triple-negative cases, particularly in metaplastic carcinomas, we attempted to determine whether claudin expression at the protein level can differentiate cases 
Table VII. Univariate analysis considering disease-free survival of breast cancer patients.

\begin{tabular}{|c|c|c|c|c|}
\hline Variables & Number of patients & Median survival (years) & $95 \%$ confidence interval & P-value \\
\hline \multicolumn{5}{|l|}{ Pathological stage } \\
\hline II & 395 & 21.0 & ND & \multirow[t]{2}{*}{$<0.001$} \\
\hline III & 350 & 5.0 & $4.0-6.0$ & \\
\hline \multicolumn{5}{|l|}{ HER-2 } \\
\hline Negative & 632 & 16.0 & $9.8-14.2$ & \multirow[t]{2}{*}{0.009} \\
\hline Positive & 106 & 8.0 & Not determined & \\
\hline \multicolumn{5}{|l|}{ Estrogen receptor } \\
\hline Negative & 248 & 8.0 & $2.1-13.8$ & \multirow[t]{2}{*}{$<0.001$} \\
\hline Positive & 497 & Not achieved & Not determined & \\
\hline \multicolumn{5}{|c|}{ Progesterone receptor } \\
\hline Negative & 403 & 10.0 & $5.7-14.3$ & \multirow[t]{2}{*}{$<0.001$} \\
\hline Positive & 342 & NA & Not determined & \\
\hline \multicolumn{5}{|c|}{ Molecular subgroups } \\
\hline Luminal A & 474 & Not achieved & Not determined & \multirow[t]{3}{*}{$<0.001$} \\
\hline HER-2 & 106 & 8.0 & Not determined & \\
\hline Triple-negative & 158 & 10.0 & $3.7-16.3$ & \\
\hline \multicolumn{5}{|l|}{ Claudin 4} \\
\hline Negative & 265 & 14.0 & $9.9-18.1$ & \multirow[t]{2}{*}{0.76} \\
\hline Positive & 469 & 21.0 & $8.0-34.0$ & \\
\hline \multicolumn{5}{|l|}{ Claudin 7} \\
\hline Negative & 337 & Not achieved & Not determined & \multirow[t]{2}{*}{0.18} \\
\hline Positive & 342 & 16.0 & Not determined & \\
\hline \multicolumn{5}{|l|}{ CD44/CD24 } \\
\hline$-/-$ & 271 & Not achieved & Not determined & \multirow[t]{4}{*}{0.93} \\
\hline$-/+$ & 231 & Not achieved & Not determined & \\
\hline$+/-$ & 78 & 16.0 & 4.8-27.2 & \\
\hline$+/+$ & 120 & 16.0 & $9.9-22.0$ & \\
\hline
\end{tabular}

HER2, human epidermal growth factor receptor 2; P-value was determined by the log-rank test; bold print indicates statistical significance.

Table VIII. Univariate analysis considering triple-negative breast cancer patients.

\begin{tabular}{|c|c|c|c|c|}
\hline Variables & Number of patients & Median survival (years) & $95 \%$ confidence interval & P-value \\
\hline \multicolumn{5}{|c|}{ Overall survival } \\
\hline Claudin 4 & & & & 0.56 \\
\hline Negative & 63 & 5.0 & $2.9-7.08$ & \\
\hline Positive & 114 & 6.0 & $2.3-9.6$ & \\
\hline Claudin 7 & & & & 0.82 \\
\hline Negative & 87 & 6.0 & $3.13-8.87$ & \\
\hline Positive & 75 & 16.0 & $3.0-10.95$ & \\
\hline \multicolumn{5}{|c|}{ Disease-free survival } \\
\hline Claudin 4 & & & & 0.35 \\
\hline Negative & 57 & 6.0 & $2.2-9.8$ & \\
\hline Positive & 99 & 15.0 & $7.3-22.6$ & \\
\hline Claudin 7 & & & & 0.79 \\
\hline Negative & 79 & 15.0 & $3.23-26.8$ & \\
\hline Positive & 63 & Not achieved & Not determined & \\
\hline
\end{tabular}

P-value was determined by the log-rank test. 
Table IX. Univariate analysis considering luminal breast cancer patients.

\begin{tabular}{lccc}
\hline Variables & Number of patients & Median survival (years) & 95\% confidence interval \\
\hline Overall survival & & & \\
Claudin 4 & 199 & 11.0 & 0.39 \\
Negative & 293 & 14.0 & $11.8-16.3$ \\
Positive & & & $10.3-15.8$ \\
Claudin 7 & 214 & Not achieved & Not determined \\
Negative & 239 & & 0.82 \\
Positive & & 13.0 & 0.70 \\
Disease-free survival & 185 & Not achieved & Not determined \\
Claudin 4 & 281 & & Not determined \\
Negative & & Not achieved & Not determined \\
Positive & 206 & Not achieved & 0.28 \\
Claudin 7 & 229 & & \\
Negative & & & \\
Positive & & & \\
\hline
\end{tabular}

P-value was determined by the log-rank test.

Table X. Univariate analysis considering HER-2-positive breast cancer patients.

\begin{tabular}{|c|c|c|c|c|}
\hline Variables & Number of patients & Median survival (years) & $95 \%$ confidence interval & P-value \\
\hline \multicolumn{5}{|c|}{ Overall survival } \\
\hline Claudin 4 & & & & 0.51 \\
\hline Negative & 21 & 4.0 & $2.7-5.3$ & \\
\hline Positive & 93 & 10.0 & $3.4-16.6$ & \\
\hline Claudin 7 & & & & 0.27 \\
\hline Negative & 51 & 11.0 & Not determined & \\
\hline Positive & 52 & 4.0 & $0.0-8.0$ & \\
\hline \multicolumn{5}{|c|}{ Disease-free survival } \\
\hline Claudin 4 & & & & 0.88 \\
\hline Negative & 20 & 4.0 & Not determined & \\
\hline Positive & 86 & 8.0 & Not determined & \\
\hline Claudin 7 & & & & 0.09 \\
\hline Negative & 50 & Not achieved & Not determined & \\
\hline Positive & 48 & 3.0 & $1.4-4.5$ & \\
\hline
\end{tabular}

HER-2, human epidermal growth factor receptor 2; P-value was determined by the log-rank test.

with worse prognosis within breast cancer molecular subtypes. Our results demonstrated that claudin 4 and 7 status was not indicative of a better or worse outcome within breast cancer subtypes. Some of the reports linking metaplastic carcinoma to claudin expression were based on immunohistochemistry results (22). Moreover, by assessing the presence of a given protein by immunohistochemistry within the tumor, the result is ensured to reflect neoplastic cells rather than normal tissue contamination. This is particularly important for claudin identification, since the claudin-low phenotype or the absence or claudin expression as a result will not be affected by the presence of stromal desmoplastic tissue samples. Unavailability of immunohistochemistry data may hinder the evaluation of the molecular subtypes, as the materials may not be sufficient for TMA analysis (20).

In summary, our results indicated that, despite claudin 4 positivity being correlated with poor prognostic factors, such as increased tumor grade, presence of positive lymph nodes and ER/PR negativity, claudin-low cases (including low expression of claudins 4 and 7) evaluated by immunohistochemistry did not correspond to triple-negative breast cancer molecular profile. Therefore, individual evaluation of claudin expression alone may not allow for an accurate correlation with the triple-negative subtype of the disease. 


\section{Acknowledgements}

The authors wish to thank Dr Mônica Maria Agata Stiepcich for compiling clinical data from TMA and Dr Maria Dirley Ferreira de Souza Begnami for performing the immunohystochemical reactions for claudins 4 and 7 .

\section{Funding}

This study received financial support from FAPESP (Fundação de Amparo à Pesquisa do Estado de São Paulo) and CNPq (Conselho Nacional de Desenvolvimento Científico e Tecnológico).

\section{Availability of data and materials}

All the data reported in the present study are available from the corresponding author upon reasonable request.

\section{Authors' contributions}

AFL, FAS and MMB designed the study and wrote the manuscript. AFL, FSP, SN, RMR collected and analyzed data. All the authors have reviewed the manuscript critically and approved the final version of this manuscript.

\section{Ethics approval and consent to participate}

The present study was conducted following approval of the local Ethics Committee. The hospital obtained informed consent forms from all patients for using archived tissues for research at any time. Patient anonymity was guaranteed.

\section{Patient consent for publication}

Not applicable.

\section{Competing interests}

The authors declare that they have no competing interests.

\section{References}

1. Marchio C, Balmativola D, Castiglione R, Annaratone L and Sapino A: Predictive diagnostic pathology in the target therapy era in breast cancer. Curr Drug Targets 18: 4-12, 2017.

2. Mardekian SK, Bombonati A and Palazzo JP: Ductal carcinoma in situ of the breast: The importance of morphologic and molecular interactions. Hum Pathol 49: 114-23, 2016.

3. Sørlie T, Perou CM, Tibshirani R, Aas T, Geisler S, Johnsen H, Hastie T, Eisen MB, van de Rijn M, Jeffrey SS, et al: Gene expression patterns of breast carcinomas distinguish tumor subclasses with clinical implications. Proc Natl Acad Sci USA 98: 10869-10874, 2001.

4. Abd El-Rehim DM, Ball G, Pinder SE, Rakha E, Paish C, Robertson JF, Macmillan D, Blamey RW and Ellis IO: High-throughput protein expression analysis using tissue microarray technology of a large well-characterised series identifies biologically distinct classes of breast cancer confirming recent cDNA expression analyses. Int J Cancer 116: 340-350, 2005.

5. Cheang MC, Chia SK, Voduc D, Gao D, Leung S, Snider J, Watson M, Davies S, Bernard PS, Parker JS, et al: Ki67 index, HER2 status, and prognosis of patients with luminal B breast cancer. J Natl Cancer Inst 101: 736-750, 2009.
6. Tang P and Tse GM: Immunohistochemical surrogates for molecular classification of breast carcinoma: A 2015 update. Arch Pathol Lab Med 140: 806-814, 2016.

7. Hagemann IS: Molecular testing in breast cancer: A guide to current practices. Arch Pathol Lab Med 140: 815-824, 2016.

8. Tan W, Li Q, Chen K, Su F, Song E and Gong C: Estrogen receptor beta as a prognostic factor in breast cancer patients: A systematic review and meta-analysis. Oncotarget 7: 10373-10385, 2016.

9. Matsumoto A, Jinno H, Ando T, Fujii T, Nakamura T, Saito J, Takahashi M, Hayashida T and Kitagawa Y: Biological markers of invasive breast cancer. Jpn J Clin Oncol 46: 99-105, 2016.

10. Lehmann U, Albat C and Kreipe H: High-resolution quantitative methylation analysis of microRNA genes using Pyrosequencing ${ }^{\mathrm{TM}}$. Methods Mol Biol 878: 229-240, 2012.

11. Hennessy BT, Gonzalez-Angulo AM, Stemke-Hale K, Gilcrease MZ, Krishnamurthy S, Lee JS, Fridlyand J, Sahin A, Agarwal R, Joy C, et al: Characterization of a naturally occurring breast cancer subset enriched in epithelial-to-mesenchymal transition and stem cell characteristics. Cancer Res 69: 4116-4124, 2009.

12. Lin X, Shang X, Manorek G and Howell SB: Regulation of the epithelial-mesenchymal transition by claudin-3 and claudin- 4 . PLoS One 8: e67496, 2013.

13. Lu S, Singh K, Mangray S, Tavares R, Noble L, Resnick MB and Yakirevich E: Claudin expression in high-grade invasive ductal carcinoma of the breast: Correlation with the molecular subtype. Mod Pathol 26: 485-495, 2013.

14. Prat A, Parker JS, Karginova O, Fan C, Livasy C, Herschkowitz JI, He X and Perou CM: Phenotypic and molecular characterization of the claudin-low intrinsic subtype of breast cancer. Breast Cancer Res 12: R68, 2010.

15. Singh AB and Dhawan P: Claudins and cancer: Fall of the soldiers entrusted to protect the gate and keep the barrier intact. Semin Cell Dev Biol 42: 58-65, 2015.

16. Khan $\mathrm{N}$ and Asif AR: Transcriptional regulators of claudins in epithelial tight junctions. Mediators Inflamm 2015: 219843, 2015.

17. Achari C, Winslow S and Larsson C: Down regulation of CLDND1 induces apoptosis in breast cancer cells. PLoS One 10: e0130300, 2015.

18. Iravani O, Yip GW, Thike AA, Chua PJ, Jane Scully O, Tan PH and Bay BH: Prognostic significance of Claudin 12 in estrogen receptor-negative breast cancer. J Clin Pathol 69: 878-883, 2016.

19. Katayama A, Handa T, Komatsu K, Togo M, Horiguchi J, Nishiyama $\mathrm{M}$ and Oyama T: Expression patterns of claudins in patients with triple-negative breast cancer are associated with nodal metastasis and worse outcome. Pathol Int 67: 404-413, 2017.

20. Dias K, Dvorkin-Gheva A, Hallett RM, Wu Y, Hassell J, Pond GR, Levine M, Whelan T and Bane AL: Claudin-low breast cancer; clinical and pathological characteristics. PLoS One 12: e0168669, 2017.

21. Lanigan F, McKiernan E, Brennan DJ, Hegarty S, Millikan RC, McBryan J, Jirstrom K, Landberg G, Martin F, Duffy MJ and Gallagher WM: Increased claudin-4 expression is associated with poor prognosis and high tumour grade in breast cancer. Int J cancer 124: 2088-2097, 2009.

22. Gerhard R, Ricardo S, Albergaria A, Gomes M, Silva AR, Logullo ÂF, Cameselle-Teijeiro JF, Paredes J and Schmitt F: Immunohistochemical features of claudin-low intrinsic subtype in metaplastic breast carcinomas. Breast 21: 354-360, 2012.

23. Rakha EA, El-Sayed ME, Lee AH, Elston CW, Grainge MJ, Hodi Z, Blamey RW and Ellis IO: Prognostic significance of nottingham histologic grade in invasive breast carcinoma. J Clin Oncol 26: 3153-3158, 2008.

24. Mangone FR, Brentani MM, Nonogaki S, Begnami MD, Campos AH, Walder F, Carvalho MB, Soares FA, Torloni H, Kowalski LP and Federico MH: Overexpression of Fos-related antigen-1 in head and neck squamous cell carcinoma. Int J Exp Pathol 86: 205-212, 2005.

25. Allred DC, Harvey JM, Berardo M and Clark GM: Prognostic and predictive factors in breast cancer by immunohistochemical analysis. Mod Pathol 11: 155-168, 1998.

26. Wolff AC, Hammond ME, Hicks DG, Dowsett M, McShane LM, Allison KH, Allred DC, Bartlett JM, Bilous M, Fitzgibbons $\mathrm{P}$, et al: Recommendations for human epidermal growth factor receptor 2 testing in breast cancer: American Society Of Clinical Oncology/College of American Pathologists clinical practice guideline update. Arch Pathol Lab Med 138: 241-256, 2014. 
27. Wolff AC, Hammond ME, Hicks DG, Dowsett $M$ McShane LM, Allison KH, Allred DC, Bartlett JM, Bilous M, Fitzgibbons P, et al: Recommendations for human epidermal growth factor receptor 2 testing in breast cancer: American Society of Clinical Oncology/College of American Pathologists clinical practice guideline update. J Clin Oncol 31: 3997-4013, 2013.

28. Bernardi MA, Logullo AF, Pasini FS, Nonogaki S, Blumke C, Soares FA and Brentani MM: Prognostic significance of CD24 and claudin-7 immunoexpression in ductal invasive breast cancer. Oncol Rep 27: 28-38, 2012

29. Carey LA, Perou CM, Livasy CA, Dressler LG, Cowan D Conway K, Karaca G, Troester MA, Tse CK, Edmiston S, et al: Race, breast cancer subtypes, and survival in the Carolina breast cancer study. JAMA 295: 2492-2502, 2006

30. Blanchard AA, Zelinski T, Xie J, Cooper S, Penner C, Leygue E and Myal Y: Identification of claudin 1 transcript variants in human invasive breast cancer. PLoS One 11: e0163387, 2016.

31. Blanchard AA, Skliris GP, Watson PH, Murphy LC, Penner C, Tomes L, Young TL, Leygue E and Myal Y: Claudins 1, 3, and 4 protein expression in ER negative breast cancer correlates with markers of the basal phenotype. Virchows Arch 454: 647-656, 2009.

32. Morohashi S, Kusumi T, Sato F, Odagiri H, Chiba H, Yoshihara S, Hakamada K, Sasaki M and Kijima H: Decreased expression of claudin-1 correlates with recurrence status in breast cancer. Int J Mol Med 20: 139-143, 2007.

33. Kwon MJ: Emerging roles of claudins in human cancer. Int J Mol Sci 14: 18148-18180, 2013.

34. Kominsky SL, Argani P, Korz D, Evron E, Raman V, Garrett E, Rein A, Sauter G, Kallioniemi OP and Sukumar S: Loss of the tight junction protein claudin-7 correlates with histological grade in both ductal carcinoma in situ and invasive ductal carcinoma of the breast. Oncogene 22: 2021-2033, 2003.

35. Soini Y: Expression of claudins 1, 2, 3, 4, 5 and 7 in various types of tumours. Histopathology 46: 551-560, 2005.

36. Tokés AM, Kulka J, Paku S, Szik A, Páska C, Novák PK Szilák L, Kiss A, Bögi K and Schaff Z: Claudin-1, -3 and -4 proteins and mRNA expression in benign and malignant breast lesions: a research study. Breast Cancer Res 7: R296-R305, 2005

37. Kolokytha P, Yiannou P, Keramopoulos D, Kolokythas A, Nonni A, Patsouris E and Pavlakis K: Claudin-3 and claudin-4: Distinct prognostic significance in triple-negative and luminal breast cancer. Appl Immunohistochem Mol Morphol 22: 125-131, 2014.

38. Prat A and Perou CM: Deconstructing the molecular portraits of breast cancer. Mol Oncol 5: 5-23, 2011.

39. Sabatier R, Finetti P, Guille A, Adelaide J, Chaffanet M, Viens P, Birnbaum D and Bertucci F: Claudin-low breast cancers: Clinical, pathological, molecular and prognostic characterization. Mol Cancer 13: 228, 2014
40. Szasz AM, Nemeth Z, Gyorffy B, Micsinai M, Krenacs T, Baranyai Z, Harsanyi L, Kiss A, Schaff Z, Tokes AM and Kulka J: Identification of a claudin-4 and E-cadherin score to predict prognosis in breast cancer. Cancer Sci 102: 2248-2254, 2011.

41. Myal Y, Leygue E and Blanchard AA: Claudin 1 in breast tumorigenesis: Revelation of a possible novel 'claudin high' subset of breast cancers. J Biomed Biotechnol 2010: 956897, 2010.

42. Kulka J, Szász AM, Németh Z, Madaras L, Schaff Z, Molnár IA and Tokés AM: Expression of tight junction protein claudin-4 in basal-like breast carcinomas. Pathol Oncol Res 15: 59-64, 2009.

43. Prat A, Karginova O, Parker JS, Fan C, He X, Bixby L, Harrell JC, Roman E, Adamo B, Troester M and Perou CM: Characterization of cell lines derived from breast cancers and normal mammary tissues for the study of the intrinsic molecular subtypes. Breast Cancer Res Treat 142: 237-255, 2013.

44. Sauer T, Pedersen MK, Ebeltoft K and Naess O: Reduced expression of Claudin-7 in fine needle aspirates from breast carcinomas correlate with grading and metastatic disease. Cytopathology 16: 193-198, 2005.

45. Park D, Kåresen R, Axcrona U, Noren T and Sauer T: Expression pattern of adhesion molecules ((E-cadherin, alpha-, beta-, gamma-catenin and claudin-7), their influence on survival in primary breast carcinoma, and their corresponding axillary lymph node metastasis. APMIS 115: 52-65, 2007.

46. Farahani E, Patra HK, Jangamreddy JR, Rashedi I, Kawalec M, Rao Pariti RK, Batakis P and Wiechec E: Cell adhesion molecules and their relation to (cancer) cell stemness. Carcinogenesis 35: 747-759, 2014.

47. Giuliano AE, Connolly JL, Edge SB, Mittendorf EA, Rugo HS, Solin LJ, Weaver DL, Winchester DJ and Hortobagyi GN: Breast cancer-major changes in the American Joint Committee on Cancer eighth edition cancer staging manual. CA Cancer J Clin 67: 290-303, 2017.

This work is licensed under a Creative Commons Attribution-NonCommercial-NoDerivatives 4.0 International (CC BY-NC-ND 4.0) License. 